Short reports

\title{
Study of acute flaccid paralysis surveillance system in Kerman (Iran) for one decade
}

\author{
Hossein Ali Ebrahimi, Nouzar Nakhaee, Roohollah Zahmatkesh, Maraym Mirzaee
}

Kerman University of Medical Sciences, Kerman, Iran

Received 31 July 2013, Accepted 1 October 2013

(C) 2013, Ebrahimi H.A., Nakhaee N., Zahmatkesh R., Mirzaee M.

(C) 2013, Russian Open Medical Journal

\begin{abstract}
Background - During the past decade, polio eradication has stalled globally. Acute flaccid paralysis (AFP) surveillance is a key strategy for monitoring the progress of polio eradication. All AFP patients who referred to expert committee were evaluated about the causes. Methods - This case series study is the result of activities for one decade of expert AFP committee of Kerman University of Medical Sciences from 2002-2011, with coverage of more than 2,650,000 populations and 730,677 child with age of $\leq 15$ years old. All patients have gone under diagnostic and therapeutic managements. Results - The total cases referred to Kerman expert committee of AFP for ten years were 147 cases. In our study the incidence of AFP was 2.016 per 100000 populations for one year. The most common causes of AFP were Guillain-Barre syndrome (GBS). Other causes of AFP were; stroke, synovitis, myelitis, seizures, cerebral palsy, viral infections, tumors, cerebellitis and non-polio AFP. The rate of GBS in our study was 0.96 per 100000 in children 15 years old or smaller, and more in male. In this study the incidence rate in cities with low mean temperature was higher than in cities with high mean temperature. Conclusion - We had no polio case in this period. The most common cause of AFPs was Guillain-Barre syndrome. The incidence of GBS was higher in areas with low mean temperature.
\end{abstract}

Keywords: Polio eradication, Acute flaccid paralysis, Guillain-Barre syndrome

Cite as Ebrahimi HA, Nakhaee N, Zahmatkesh R, Mirzaee M. Study of acute flaccid paralysis surveillance system in Kerman (Iran) for one decade. Russian Open Medical Journal 2014; 3: 0104.

Correspondence to Nouzar Nakhaee. Address: P.O. Box 76175-113, Kerman, Iran. Phone: +98-341-2264196. Email \#1: nakhaeen@yahoo.com.

E-mail \#2: nakhaeen@kmu.ac.ir

\section{Introduction}

During the past decade, polio eradication has stalled globally. In Iran there is a unit in charge of polio eradication activities. In each province, the Vice-chancellor of the University of Medical Sciences is responsible for implementation of polio eradication activities, which include acute flaccid paralysis (AFP). AFP surveillance is a key strategy for monitoring the progress of polio eradication and is a sensitive instrument for detecting potential poliomyelitis cases and poliovirus infection [1]. All AFP patients who referred to expert committeeevaluated about the causes. There are several causes for differential diagnosis, Guillain Barre Syndrome (GBS), cerebral infarction, myelitis, cerebral palsy, synovitis, encephalitis, tumors, peripheral neuropathy, seizures and metabolic disorders [1]. The most important and most common is Guillain Barre syndrome, since the disappearance of polio in 2000 in Bangladesh, a high incidence of acute flaccid weakness in Bangladeshi children (3.25 cases per 100,000) is still present but is now related mostly to GBS. Frequent exposure to enteric pathogens at an early age may increase this incidence of GBS [2].

GBS is an autoimmune-mediated disease with environmental triggers (eg, pathogenic or stressful exposures). Several infections (e.g., Epstein-Barr virus, cytomegalovirus, hepatitis, varicella, other herpes viruses, Mycoplasma pneumoniae, Campylobacter jejuni) as well as immunizations have been known to precede or to be associated with the illness. Campylobacter jejuni seems to be the most commonly described pathogen associated with GBS. Occasionally, surgery has been noted to be a precipitating factor, and venom snake has been reported too [2].

Males appear to be at greater risk for GBS than females. This increased predilection for GBS has also been reported as a maleto-female ratio of 1.2:1 in a review of children with GBS. A similar ratio of 1.26:1 was found in a prospective study of 95 children with GBS in Western Europe [3]. Some expert committee of AFP in University of medical sciences in Iran published the results of polio eradications [4].

In this study we evaluated the causes of AFP in children with ages 15 years old or below in Kerman province at the time of ten years after eradication of polio.

\section{Material and Methods}

This case series study is result of activities for one decade of expert AFP committeeof Kerman University of medical sciences from 2002-2011 by helping of Vice-chancellor of health evaluated. The area of this is Kerman province (except Rafsanjan city due to independent Rafsanjan University medical science from Kerman University of medical sciences) with more than 2,650,000 populations and 730,677 child with age of $\geq 15$ years old. The data entered in a special form. The variables included were; age, sex, city of life, month, season and year of involvement, the outcome after 60 days. All patients have gone under diagnostic and 
therapeutic managements [5]. The Guillain-Barre syndrome patients examined and managed by neurologist.

The data were described by SPSS version 20 .

\section{Results}

The total cases referred to Kerman expert committee of AFP for ten years (1381-1390) were 147 cases of whom 18 cases were Afghan immigrants. The distribution of AFP cases (GBS and NonGBS) per years showed in Table 1.

Seasonal distribution of AFP (GBS and Non-GBS) cases showed in Table 2.

Age and sex distribution of AFP (GBS and Non-GBS) cases showed in Table 3.

The final diagnosis of AFP cases showed in Table 4.

We followed the GBS cases at 60 days after AFP beginning and the rate of recovery evaluated. 3 cases have died, 18 cases have complete recovery, 36 cases have mild disability, 8 cases have moderate disability, and 5 cases have not recovery.

\section{Discussion}

AFP flaccid paralysis is a clinical syndrome characterized by rapid onset of weakness, including (less frequently) weakness of the muscles of respiration and swallowing, progressing to maximum severity within several days to weeks. The term "flaccid" indicates the absence of spasticity or other signs of disordered central nervous system motor tracts such as hyperreflexia, clonus, or extensor plantar responses [6].

The differential diagnosis of AFP varies considerably with age. No single operational clinical case definition of AFP or paralytic poliomyelitis that combines both high sensitivity and high specificity has emerged $[7,8]$.

The annual incidence globally is $1-2$ per 100,000 populations [9]; however, there are differences by region and ethnicity. Guillain-Barre syndrome is an important cause of AFP among children, but rarely, cases in infants have been reported [10].The incidence of AFP 1.6/100000 at any age, and 1 per 100,000 in children under 15 years old, the GBS was the most common diagnosis, 0.8 per $100,000[11,12]$. In our study the incidence of AFP is 2.016 per 100,000 populations for one year. In this study the incidence is higher than some reports; this finding may be due to variation of differential diagnosis. The overall incidence of GBS was between 1.1/100,000/year and 1.8/100,000/year in Europe and NorthAmerica. The incidence of GBS increased with age after 50 years from $1.7 / 100,000 /$ year to $3.3 / 100,000 /$ year $[13,14]$. The overall incidence in military person of USA was $2.28 / 100,000$ persons, is higher than general population, the majority of cases were male [15]. In Sweden the incidence is moderately higher and is more in male than female [16].

The rate GBS in our study is 0.96 per 100000 in children 15 years old or smaller. In this study $47 \%$ of AFP cases were GBS, in a study of Iran this rate is $0.88-1.3 / 100000$ child $\geq 15$ years old [17], but in WHO report this is $20 \%$ [18]. In Oman country the rate GBS is $0.45 / 100000$ and it's lower than our study [19], may be due to high mean temperature in Oman country like the southern cities of Kerman Province, but in WHO report this rate is 0.5-1.5\% [20]. Other causes of AFP are include; stroke, synovitis, myelitis, seizures, cerebral palsy, viral infections, tumors, cerebellitis and Non-polio AFP (Table 4). These findings are same as other reports [21-25]. In this study the rate of incidence in cities with low mean temperature higher than in cities with high mean temperature. This finding is same as other nervous system autoimmune disorders (multiple sclerosis, GBS) to under published research of first author. This findings approved the low mean temperature of area may be a positive role on incidence of autoimmune disease.

In this study we find an increase incidence of GBS at 1387 (2008-2009), but we can't find any factor about it (Table 1). May be an infection or vaccination and other factors have involved, like the increase incidence after $\mathrm{NiH} 1$ vaccination [26].

The incidence rate of GBS is more in spring season (Table 2). In this season the allergic reactions are more.

Table 1. Distribution of AFP cases (GBS and Non-GBS) on the years

\begin{tabular}{lccc}
\hline Year & GBS & Non-GBS & Total \\
\hline $1381(2002-2003)$ & 7 & 2 & 9 \\
$1382(2003-2004)$ & 4 & 3 & 7 \\
$1383(2004-2005)$ & 2 & 8 & 10 \\
$1384(2005-2006)$ & 9 & 1 & 10 \\
$1385(2006-2007)$ & 6 & 20 & 26 \\
$1386(2007-2008)$ & 6 & 11 & 17 \\
$1387(2008-2009)$ & 15 & 9 & 24 \\
$1388(2009-2010)$ & 8 & 8 & 16 \\
$1389(2010-2011)$ & 4 & 6 & 10 \\
$1390(2011-2012)$ & 9 & 9 & 18 \\
Total & 70 & 77 & 147 \\
\hline
\end{tabular}

Table 2. Distribution of AFP cases on the seasons

\begin{tabular}{lccc}
\hline Season & GBS & Non-GBS & Total \\
\hline Spring & 24 & 24 & 48 \\
Summer & 21 & 15 & 36 \\
Fall & 14 & 23 & 37 \\
Winter & 11 & 15 & 26 \\
\hline
\end{tabular}

Table 3. Distribution of AFP cases on age and sex

\begin{tabular}{lccc}
\hline Cases & GBS & Non-GBS & Total \\
\hline Age, $\mathrm{M} \pm \mathrm{SD}$ & $5.8 \pm 3.9$ & $4 \pm 3$ & $4.9 \pm 3.6$ \\
Male, $\mathrm{n}(\%)$ & $38(54.3 \%)$ & $42(54.5 \%)$ & $80(54.4 \%)$ \\
Female, $\mathrm{n}(\%)$ & $32(45.7 \%)$ & $35(45.5 \%)$ & $67(45.6 \%)$ \\
Total, $\mathrm{n}(\%)$ & 70 & 77 & \\
\hline
\end{tabular}

$\mathrm{M}$, mean; SD, standard deviation.

Table 4. Final diagnosis of AFP cases

\begin{tabular}{lc}
\hline Final Diagnosis & Number \\
\hline GBS & 70 \\
Stroke & 8 \\
Synovitis & 19 \\
Electrolite disturbances & 9 \\
Seizures & 5 \\
Cerebral Palsy & 4 \\
Encephalitis or Viral infections & 7 \\
Tumors (Brain or Spinal) & 4 \\
Cerebellitis & 2 \\
Non-polio AFP & 1 \\
TB or Abscess of Spine & 3 \\
Trauma of Spine & 2 \\
Transvers myelitis & 3 \\
Poisoning & 1 \\
\hline
\end{tabular}


Table 5. The outcome of GBS cases after $\mathbf{6 0}$ days

\begin{tabular}{lcc} 
Outcome & Number & Percent \\
\hline Complete recovery & 18 & $26 \%$ \\
Mild disability & 37 & $52 \%$ \\
Moderate disability & 8 & $11 \%$ \\
Sever disability & 5 & $7 \%$ \\
Death & 3 & $4 \%$ \\
\hline
\end{tabular}

Some of patients are non-Iranian nationality (from Afghanistan), because there are a lot of immigration from Afghanistan in Kerman. The mean age of patients in children with 15 years old or smaller in this study is 5.8 (Table 3 ), this finding as same as other reports $[27,28]$. In this study the patients are often male (Table 3), this finding is same as other reports from other countries $[29,30]$. GBS incidence increased by $20 \%$ for every $10-$ year increase in age; the risk of GBS was higher for males than females [31]. Majority of patients improved with supportive treatment alone, in this study after 60 days follow up more than $75 \%$ cases full recovered or have only mild disability, the $18 \%$ cases have moderate to severe disability, and $4 \%$ of patients with GBS have died (Table 5). In a study the rate recovery after 3 months reported $50 \%$ and the rate of death was $7.4 \%$ [32]. The differences may be due to low age of our patients that were 15 years old or smaller. In general, the outcome of GBS is more favorable in children than in adults. Deaths are relatively rare, especially if the disorder is diagnosed and treated early. However, the recovery period is long, often weeks to months, with a median estimated recovery time of 6-12 months. In one small pediatric series, the median time from onset of symptoms to complete recovery was 73 days. Full recovery within 3-12 months is experienced by $90-95 \%$ of pediatric patients with GBS. Between $5 \%$ and $10 \%$ of individuals have significant permanent disabilities. The prognosis of GBS is generally favorable, but it is a serious disease with a mortality of approximately $10 \%$ and approximately $20 \%$ of patients are left with severe disability [33,34].

Overall mortality rate in childhood GBS is estimated to be less than 5\%; mortality rates are higher in medically underserved areas. Mechanically ventilated patients constitute the majority of GBS patients with a poor outcome, and mortality remains substantial in this subgroup (20\%). Although recovery from severe GBS may be prolonged, most survivors regain independent ambulation [35]. Persistent disability is seen in $20-30 \%$ of adult patients but is less common in children [36, 37]. GBS causes severe persistent disability in $14 \%$ of patients at 1 year. Loss of full strength, persistent pain and need for professional change occurs in about $40 \%$. Mortality is of about $4 \%$ within the first year [38].

\section{Conclusion}

In sum, GBS, synovitis and Electrolite disturbances were the most common diagnoses. There was no proven case of poliomyelitis.

Conflict of interest: none declared.

\section{References}

1. Marx A, Glass JD, Sutter RW. Differential diagnosis of acute flaccid paralysis and its role in poliomyelitis surveillance. Epidemiol Rev 2000; 22(2): 298-316. (PMID: 11218380)
2. Frenzen PD. Economic cost of Guillain-Barré syndrome in the United States. Neurology 2008; 71(1): 21-27. (doi: 10.1212/01.wnl.0000316393.54258.d1)

3. Jones HR. Childhood Guillain-Barre syndrome: clinical presentation, diagnosis, and therapy. J Child Neurol 1996; 11: 4-12.

4. Davarpanah MA, Bakhtiari H, Mehrabani D, Khademolhosseini F. A 12Years Surveillance of Poliomyelitis and Acute Flaccid Paralysis in Fars Province, Southern Iran. IRCMJ 2008; 10(4): 288-293.

5. Kannan MA, Ch RK, Jabeen SA, Mridula KR, Rao P, Borgohain R. Clinical, electrophysiological subtypes and antiganglioside antibodies in childhood Guillain-Barré syndrome. Neurol India 2011; 59(5): 727-732. (PMID: 22019659) (doi: 10.4103/0028-3886.86549)

6. Singhi SC, Sankhyan N, Shah R, Singhi P. Approach to a child with acute flaccid paralysis. Indian J Pediatr 2012; 79(10): 1351-1357. (PMID: 22791354) (doi: 10.1007/s12098-012-0831-8)

7. Andrus JK, de Quadros C, Olivé JM, Hull HF. Screening of cases of acute flaccid paralysis for poliomyelitis eradication: ways to improve specificity. Bull World Health Organ 1992; 70: 591-596. (PMID: 1281445) (PMCID: PMC2393371)

8. Dietz V, Lezana M, Garcia Sancho C, Montesano R. Predictors of poliomyelitis case confirmation at initial clinical evaluation: implications for poliomyelitis eradication in the Americas. Int J Epidemiol 1992; 21: 800-806. (doi: 10.1093/ije/21.4.800) (PMID: 1521986)

9. Kennedy RH, Danielson MA, Mulder DW, Kurland LT. Guillain-Barre syndrome: a 42-year epidemiologic and clinical study. Mayo Clin Proc 1978; 53: 93-99. (PMID: 621963)

10. Ascherio A, Bermudez CS, Garcia D. Outbreak of buckthorn paralysis in Nicaragua. J Trop Pediatr 1992; 38(2): 87-89. (PMID: 1569643) (doi: 10.1093/tropej/38.2.87)

11. Hovi T, Stenvik M. Surveillance of patients with acute flaccid paralysis in Finland: report of a pilot study. Bull World Health Organ 2000; 78(3): 298-304. (PMID: 10812725) (PMCID: PMC2560699)

12. Dietz V, Andrus J, Olivé JM, Cochi S, de Quadros C. Epidemiology and clinical characteristics of acute flaccid paralysis associated with nonpolio enterovirus isolation: the experience in the Americas. Bull World Health Organ 1995; 73(5): 597-603. (PMID: 8846485) (PMCID: PMC2486829)

13. Olivé JM, Castillo C, Castro RG, de Quadros CA. Epidemiologic study of Guillain-Barre syndrome in children $<15$ years of age in Latin America. J Infect Dis 1997; 175(suppl 1): S160-S164. (PMID: 9203710) (doi: 10.1093/infdis/175.Supplement_1.S160)

14. McGrogan A, Madle GC, Seaman HE, de Vries CS. The epidemiology of Guillain-Barré syndrome worldwide. A systematic literature review. Neuroepidemiology 2009; 32(2): 150-163. (doi: 10.1159/000184748) (PMID: 19088488)

15. Nelson L, Gormley R, Riddle MS, Tribble DR, Porter CK. The epidemiology of Guillain-Barré Syndrome in U.S. military personnel: a case-control study. BMC Research Notes 2009; 2: 171. (doi: 10.1186/1756-0500-2-171)

16. Cheng $Q$, Jiang GX, Fredrikson S, Link H, De Pedro-Cuesta J. Incidence of Guillain-Barré syndrome in Sweden 1996. Eur J Neurol 2000; 7(1): 11-16. (PMID: 10809910)

17. Esteghamati A, Keshtkar A, Gooya MM, Zahraee M, Dadras MN, Moosavi T. Relationship between Occurrence of Guillan-Barre Syndrome and Mass Campaign of Measles and Rubella Immunization in Iranian 5-14 Years Old Children. Iranian Journal of Pediatrics 2007; 17(Supll 2): 217-223.

18. Koul RL, Chacko A, Sulaiman AJM, Mehta FR. Epidemiology and clinical profile of childhood Guillain-Barré Syndrome in Oman. Middle East Pediatrics 1998; 3: 41-44.

19. Koul R, Al-Futaisi A, Chacko A, Fazalullah M, Nabhani SA, Al-Awaidy S., et al. Clinical characteristics of childhood guillain-barré syndrome. Oman Med J 2008; 23(3): 158-161. (PMID: 22359705) (PMCID: PMC3282330) 
20. Sladky JT. Guillain-Barré syndrome in children. J Child Neurol 2004; 19: 191-200. (PMID: 15119480)

21. Jin K, Takeda A, Shiga $Y$, Sato S, Ohnuma A, Nomura H, et al. CSF tau protein: a new prognostic marker for Guillain-Barré syndrome. Neurology 2006; 67(8): 1470-1472. (PMID: 17060576)

22. D'Errico MM, Barbadoro P, Bacelli S, Esposto E, Moroni V, Scaccia F, et al. Surveillance of acute flaccid paralysis in the Marches region (Italy): 1997-2007. BMC Infectious Diseases 2008, 8: 135. (PMCID: PMC2576306) (doi: 10.1186/1471-2334-8-135) (PMID: 18844987)

23. Acute flaccid paralysis. FETP Saudi Epidemiology Bulletin 1994; 1(5): 56.

24. Poorolajal J, Ghasemi S, Farahani LN, Hosseini AS, Bathaei SJ, Zahiri A. Evaluation of acute flaccid paralysis in hamadan, iran from 2002 to 2009. Epidemiol Health 2011; 33: e2011011. (PMID: 22111031) (doi: 10.4178/epih/e2011011) (PMCID: PMC3221035)

25. Morris AM, Elliott EJ, D'Souza RM, Antony J, Kennett M, Longbottom $\mathrm{H}$. Acute flaccid paralysis in Australian children. J Paediatr Child Health 2003; 39(1): 22-26. (doi: 10.1046/j.1440-1754.2003.00065.x) (PMID: 12542807)

26. Lavelle TA, Meltzer MI, Gebremariam A, Lamarand K, Fiore AE, Prosser LA. Community-based values for 2009 pandemic influenza A H1N1 illnesses and vaccination-related adverse events. PLoS One 2011; 6(12): e27777. (doi: 10.1371/journal.pone.0027777) (PMID: 22205927) (PMCID: PMC3242758)

27. Berlit $P$, Rakicky J. The Miller Fisher syndrome. Review of the literature. J Clin Neuroophthalmol 1992; 12(1): 57-63. (PMID: 1532603)

28. Chiba A, Kusunoki S, Obata H, Machinami R, Kanazawa I. Serum antiGQ1b IgG antibody is associated with ophthalmoplegia in Miller Fisher syndrome and Guillain-Barré syndrome: clinical and immunohistochemical studies. Neurology 1993; 43(10): 1911-1917. (PMID: 8413947)

29. Grand'Maison F, Feasby TE, Hahn AF, Koopman WJ. Recurrent GuillainBarré syndrome. Clinical and laboratory features. Brain 1992; 115(Pt 4): 1093-1106. (PMID: 1393505) (doi: 10.1093/brain/115.4.1093)

30. Rasul CH, Das PL, Alam S, Ahmed S, Ahmed M. Clinical profile of acute flaccid paralysis. Med J Malaysia 2002; 57(1): 61-65. (PMID: 14569719)

31. Sejvar JJ, Baughman AL, Wise M, Morgan OW. Population incidence of Guillain-Barré syndrome: a systematic review and meta-analysis. Neuroepidemiology 2011; 36(2): 123-133. (doi: 10.1159/000324710)

32. Sagar sharma K, Singh R, Shah GS. Guillain Barre Syndrome: Major Cause of Acute Flaccid Paralysis in Children and Adolescents of Nepal. $J$ Nep Paedtr Soc 2010; 31(2): 93-97. (doi: 10.3126/jnps.v31i2.4065)

33. Kuwabara S. Guillain-Barré syndrome: epidemiology, pathophysiology and management. Drug 2004; 64(6): 597-610. (PMID: 15018590)

34. Hughes RA, Cornblath DR. Guillain-Barré syndrome. Lancet 2005; 366(9497): 1653-1666. (doi: 10.1016/S0140-6736(05)67665-9) (PMID: 16271648)

35. Fletcher DD, Lawn ND, Wolter TD, Wijdicks EF. Long-term outcome in patients with Guillain-Barré syndrome requiring mechanical ventilation. Neurology 2000; 54(12): 2311-2315. (PMID: 10881259)

36. Chiò A, Cocito D, Leone M, Giordana MT, Mora G, Mutani R, et al. Guillain-Barré syndrome: A prospective, population based incidence and outcome survey. Neurology 2003; 60: 1146-1150. (PMID: 12682322)

37. Bradshaw DY, Jones HR Jr. Guillain-Barré syndrome in children: Clinical course, electrodiagnosis, and prognosis. Muscle Nerve 1992; 15: 500506. (PMID: 1565119)

38. Rajabally YA, Uncini A. Outcome and its predictors in Guillain-Barre syndrome. J Neurol Neurosurg Psychiatry 2012; 83(7): 711-718. (doi: 10.1136/jnnp-2011-301882)

Authors:

Hossein Ali Ebrahimi - MD, Professor of Neurology, Neurology Research

Center, Kerman University of Medical Sciences, Kerman, Iran;
Nouzar Nakhaee - MD, Professor of Community Medicine, Neuroscience Research Center, Kerman University of Medical Sciences, Kerman, Iran; Roohollah Zahmatkesh - General Practitioner, Research Center for Health Services Management, Kerman University of Medical Sciences, Kerman, Iran;

Maraym Mirzaee - Expert in disease control, Research Center for Social Determinants of Health, Kerman University of Medical Sciences, Kerman, Iran. 